\title{
E-MRS Announces Call for Symposia Topics for 2005 and 2006
}

The European Materials Research Society (E-MRS) is seeking proposals for symposia topics for the 2005 E-MRS Spring Meeting to be held May 31-June 3 in Strasbourg, France and for the 2006 E-MRS-IUMRS-ICEM (International Conference on Electronic Materials). Submitted proposals (1-2 pages) must include the sym- posium title; brief state-of-the-art statement; the motivation and aim for discussion; a list of sub-topics; and the names of the symposium chairs, 2-5 from different countries. A short curriculum vitae should be supplied for the lead chair, along with the five most relevant and recent publications (1998-2003) in the field of the symposium.
Proposals should be sent by e-mail to emrs@phase.c-strasbourg.fr by March 31, 2004. Decisions will be made before the 2004 E-MRS Spring Meeting in May.

H. GRIMMEISS

E-MRS President

P. SIFFERT

E-MRS General Secretary 